УДК 504.06:504.064

DOI: https://doi.org/10.26642/ten-2020-1(85)-249-253
И.И. Чоботько, аспирант

Национальный технический университет "Днепровская политехника»

С.В. Тынына, к.т.н.

Институт геотехнической механики им. Н.С. Полякова НАН Украинь

\title{
Рентгенофлуоресцентное исследование химического состава образцов породного отвала
}

В статье проведено рентгенофлуоресиентное исследование химического состава двух образиов породы, взятых из породного отвала, при помощи настольного рентгенофлуоресцентного анализатора (РФA) - спектрометра «ElvaX Plus». B качестве образиов породы использовался материал породного отвала нерабочего террикона иахть им. Т.Г. Шевченко (г. Покровск) в виде перегоревшей породы. Образеи № 2- порода из очага горения породного отвала того же террикона.

Целью данной работы является сравнительный анализ химического состава образцов породы на наличие: $\mathrm{CaO}, \mathrm{SiO}_{2}, \mathrm{Al}_{2} \mathrm{O}_{3} ; \mathrm{K}_{2} \mathrm{O}, \mathrm{Fe}_{2} \mathrm{O}_{3}, \mathrm{MgO}$, $\mathrm{TiO}_{2}, \mathrm{~S}$ во время и после процесса горения отвала.

По результатам данных спектрального анализа установлено изменение состава $u$ концентрации химических веществ в образцах до и после окисления. Показано, что концентрация серы (S), которая является кочевым химическим элементом в самовозгорании породных отвалов в образие породы № 2, изъятой из очага горения, значительно будет превышать конщентрацию серы в породе перегоревщего образиа № 1 .

Ключевые слова: рентгенофлуоресцентное исследование химического состава; породный отвал; спектрометр; образец породы; очаг горения; концентрация веществ.

Постановка проблемы. При добыче, хранении и транспортировании самовозгораются многие твердые горючие ископаемые. Причем самовозгораются не только угли, горючие сланцы и торфы, но и некоторые породы, которые принято считать пустыми. Причинами самовозгорания служит процесс физико-химической реакции окисления, протекающей во всем объеме отвала. Самовозгорание - это процесс перехода химической системы из низкотемпературного состояния в состояние горения вследствие образования тепла внутри системы без притока тепла извне. Основным запускающим фактором для горения и одновременно подпиткой очага возгорания служит кислород, за счет конвекции происходит подсос воздуха системой извне у основания очага. Основной задачей является проведение исследований на наличие химических элементов, которые провоцируют горение всего отвала в целом. Поэтому столь важен мониторинг и анализ химического состава вещающих пород отвала [1-3].

Анализ последних исследований. На основании многолетних исследований ведущими учеными Донецкого национального технического университета М.П. Сборщиком и В.В. Осокиным, была обоснована одна из причин самовозгорания и горения пород отвалов. Для лучшего понимания процесса возгорания породы необходимо детальное изучение химического состава отвальной массы, известно, что на горение массы породы в отвале запускающим химическим элементом есть сера (S) [3, 4]. Нельзя исключать и частицы вмещающего угля в отвальной массе, механическое воздействие на уголь, имеющее место погрузке и транспортировке, что приводит к разрыву отдельных химических связей с образованием свободных радикалов, которые провоцируют развитие окислительных реакций $[5,6]$.

Цель исследования. Определение закономерностей изменения химического состава элементов в образцах породы из отвальной массы породного отвала путем рентгенофлуоресцентного спектрального анализа. Целью исследования является понять основные химические реакции, которые происходят в очаге горения и после прекращения процесса длительного горения (перегоревшая порода).

Изложение основного материала. Описание спектрометра. Рентгенофлуоресцентный настольный РФА спектрометр «ElvaX Plus», который представлен на рисунке 1. Предназначен для оперативного качественного и количественного анализа состава металлических сплавов, порошков, жидкостей, отложений на фильтрующих элементах. Анализатор оснащен системой подачи гелия и смены фильтров, что в сочетании с новым детектором Fast SDD, позволяющим осуществлять анализ легких элементов с высокой чувствительностью. 

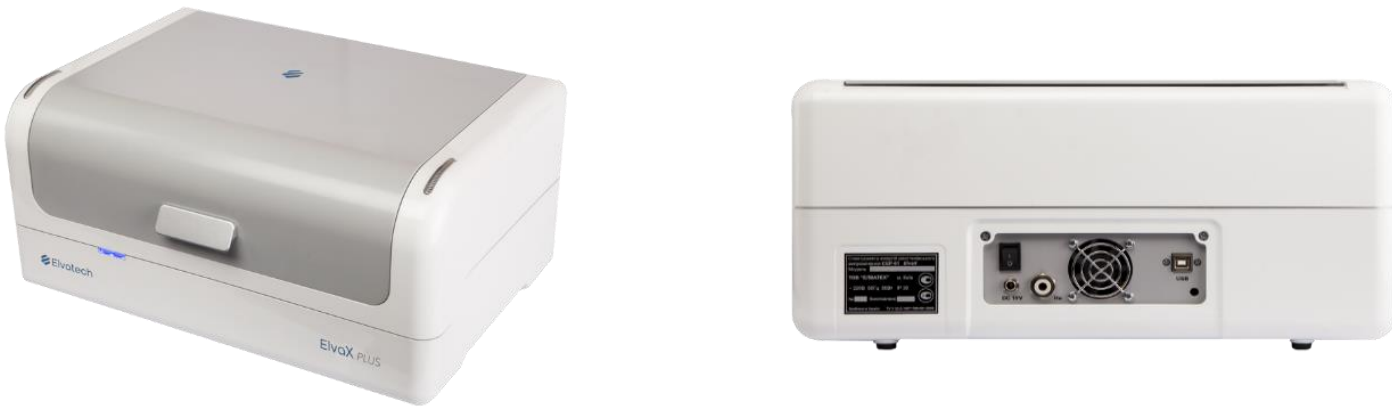

Puc. 1. Изображение спектрального анализатора «ElvaX Plus»

Исследование было проведено на базе Национального технического университета «Днепровская политехника». Для исследования было отобрано две пробы образцов породы из породного отвала (рис. 2), введенного в эксплуатацию в 1964 г. и выведенного из эксплуатации в 1989 г. бывшей шахты им. Т.Г. Шевченко, ПАО «Шахтоуправления «Покровское» в г. Покровск Донецкой области [7].
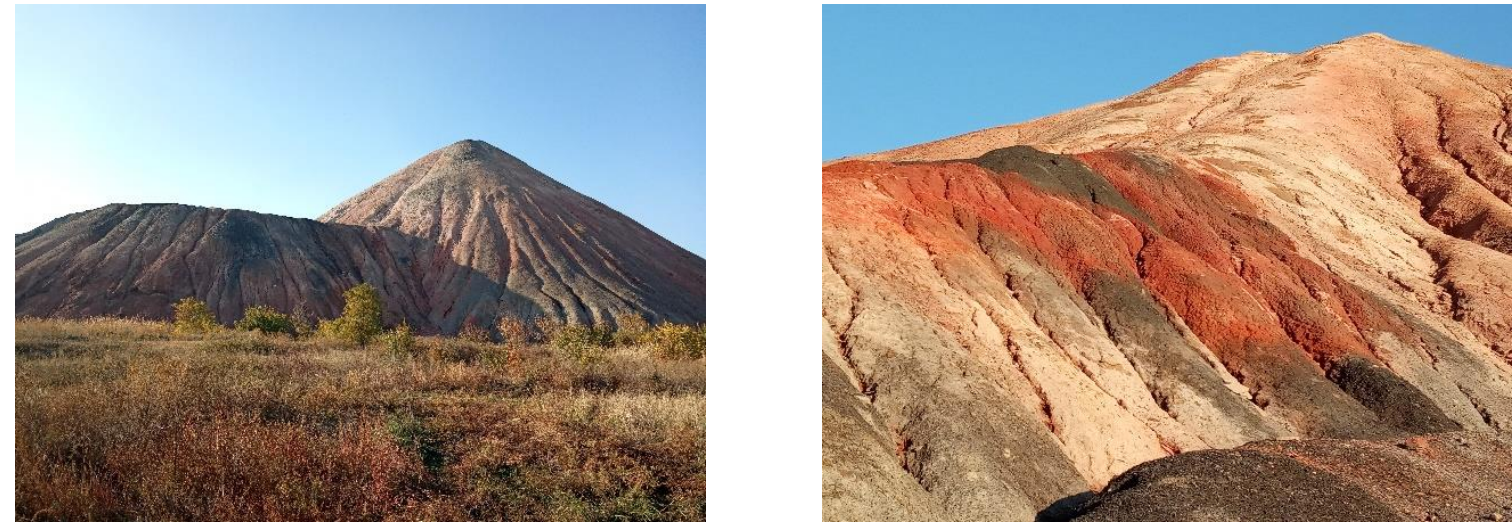

Рис. 2. Породный отвал ПАО «Шахтоуправления «Покровское»

Первый образец породы представляет собой перегоревший оплавленный кусок, спайку из различных вмещающих пород (рис. 3) массой 48 гр. при температуре около 800-1200 ${ }^{\circ} \mathrm{C}$. Данный образец для исследования был перетерт через сито размером в 0,001 мм, масса полученного порошка составила \pm 2 гр [8].
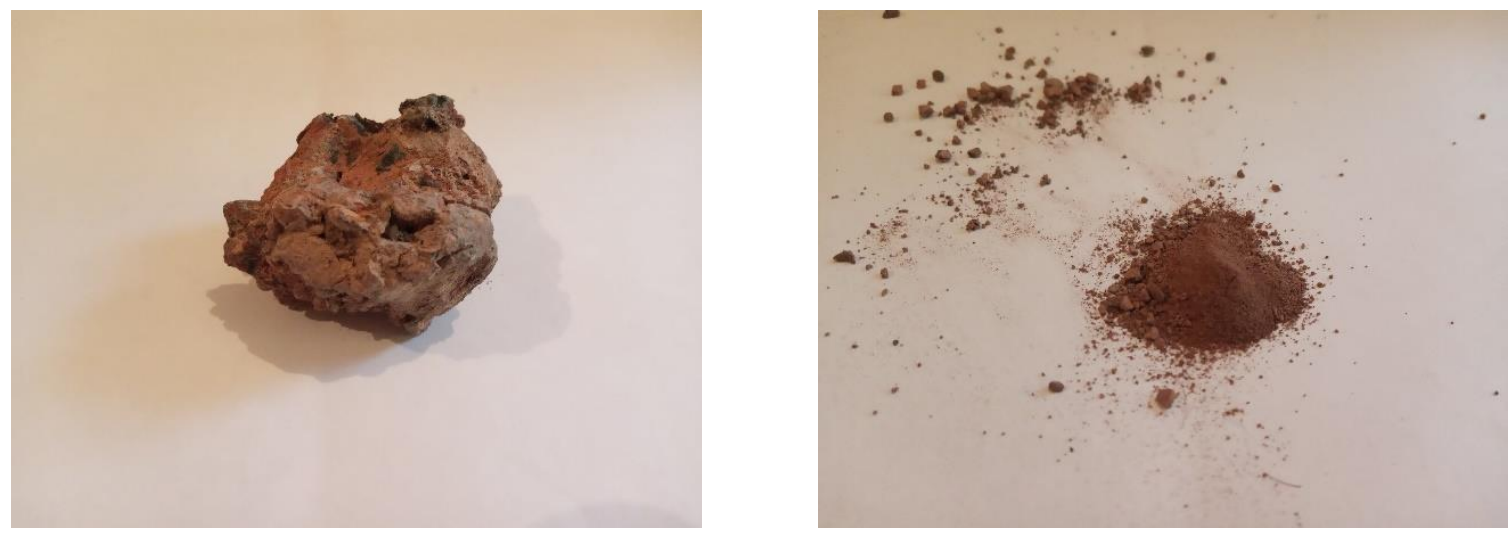

Рис. 3. Образец № 1 (перегоревшая порода)

После проведения рентгенофлуоресцентного исследования была получена таблица (табл. 1), в которой видно, что наибольшую концентрацию составляет диоксид кремния $\left(\mathrm{SiO}_{2}\right)-65,13 \%$, на втором месте - оксид алюминия $\left(\mathrm{Al}_{2} \mathrm{O}_{3}\right)-23,45 \%$, на третьем месте - оксид калия $\left(\mathrm{K}_{2} \mathrm{O}\right)-4,92 \%$ и содержание основного химического элемента горения серы (S) - 0,55 \% [9]. 
Из таблицы 1 видно, что содержание серы не доходит до 1 \%, это говорит о выгорании данного химического элемента. На графике (рис. 4) наглядно показано, что наибольшую интенсивность при альфаоблучении показывает оксид железа $\left(\mathrm{Fe}_{2} \mathrm{O}_{3}\right)-\mathrm{K} \alpha=5589681$, после него диоксид кремния $\left(\mathrm{SiO}_{2}\right)-$ К $\alpha=1562080$, оксид калия $\left(\mathrm{K}_{2} \mathrm{O}\right)-\mathrm{K} \alpha=976391$ и серы $(\mathrm{S})-\mathrm{K} \alpha=515989$.

Химические элементы в образие № 1 (перегоревшая порода)

Таблииа 1

\begin{tabular}{|c|c|c|c|c|c|}
\hline $\begin{array}{c}\text { № } \\
\text { з/п }\end{array}$ & Ат. номер & Элемент & Серия & Интенсивность & Концентрация \\
\hline 1 & 20 & $\mathrm{CaO}$ & $\mathrm{K}$ & 202159 & $0,82 \pm 0,01 \%$ \\
\hline 2 & 14 & $\mathrm{SiO}_{2}$ & $\mathrm{~K}$ & 1562080 & $65,13 \pm 0,08 \%$ \\
\hline 3 & 13 & $\mathrm{Al}_{2} \mathrm{O}_{3}$ & $\mathrm{~K}$ & 315083 & $23,45 \pm 0,08 \%$ \\
\hline 4 & 19 & $\mathrm{~K}_{2} \mathrm{O}$ & $\mathrm{K}$ & 976391 & $4,92 \pm 0,02 \%$ \\
\hline 5 & 26 & $\mathrm{Fe}_{2} \mathrm{O}_{3}$ & $\mathrm{~K}$ & 5589681 & $2,24 \pm 0,00 \%$ \\
\hline 6 & 12 & $\mathrm{MgO}$ & $\mathrm{K}$ & 10443 & $2,12 \pm 0,10 \%$ \\
\hline 7 & 22 & $\mathrm{TiO}_{2}$ & $\mathrm{~K}$ & 349571 & $0,60 \pm 0,00 \%$ \\
\hline 8 & 16 & $\mathrm{~S}$ & $\mathrm{~K}$ & 515989 & $0,55 \pm 0,00 \%$ \\
\hline
\end{tabular}

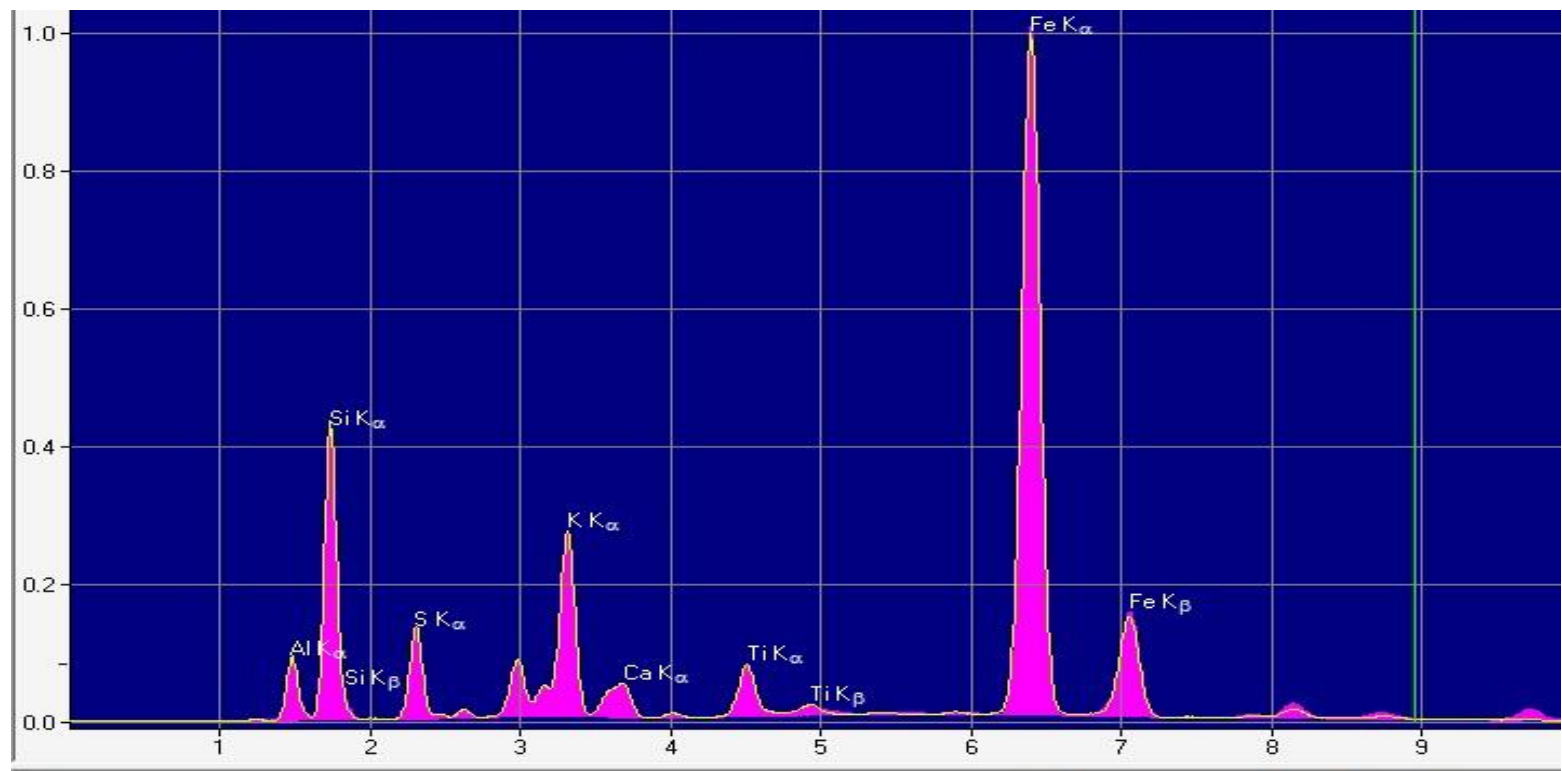

Рис. 4. Спектрограмма содержания химических элементов в образие породы № 1

Второй образец породы представляет собой породу из очага горения (рис. 5) массой 211 гр. На образце наблюдаются следы серы - желтизна на краях. Данный образец для исследования также был перетерт через сито размером в 0,001 мм, масса полученного порошка составила \pm 4 гр [10].
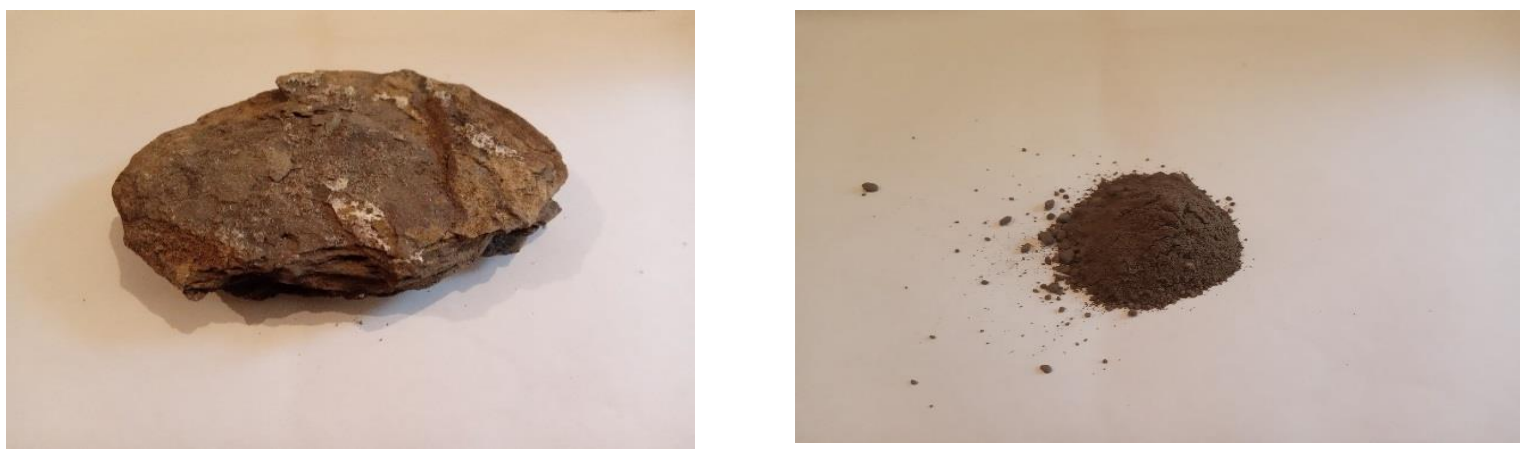

Рис. 5. Образеи, № 2 (горящฺая порода) 
После проведения рентгенофлуоресцентного исследования получена таблица (табл. 2), в которой видно, что наибольшую концентрацию составляет диоксид кремния $\left(\mathrm{SiO}_{2}\right)-73,71 \%$, на втором месте оксид алюминия $\left(\mathrm{Al}_{2} \mathrm{O}_{3}\right)-16,69 \%$, на третьем месте - оксид калия $\left(\mathrm{K}_{2} \mathrm{O}\right)-4,20 \%$ и содержание основного химического элемента горения серы $(\mathrm{S})-1,25 \%$.

Из таблицы 2 видно, что содержание серы доходит до 1,25 \%, это говорит о небольшом наличии данного химического элемента, поскольку образец был изъят с поверхности очага горения в местах выхода газов в атмосферу (трещин). Мы можем судить о большом содержании данного элемента в самом очаге. На графике (рис. 6) наглядно показано, что наибольшую интенсивность при альфаоблучении показывает оксид железа $\left(\mathrm{Fe}_{2} \mathrm{O}_{3}\right)-\mathrm{K} \alpha=3810780$, после него диоксид кремния $\left(\mathrm{SiO}_{2}\right)-\mathrm{K} \alpha=2163671$, оксид калия $\left(\mathrm{K}_{2} \mathrm{O}\right)-\mathrm{K} \alpha=920072$ и серы $(\mathrm{S})-\mathrm{K} \alpha=1317455[11,12]$.

Химические элементы в образце № 2 (горямая порода)

Таблийа 2

\begin{tabular}{|c|c|c|c|c|c|}
\hline $\begin{array}{c}\text { № } \\
\text { 3/п }\end{array}$ & Ат. номер & Элемент & Серия & Интенсивность & Концентрация \\
\hline 1 & 20 & $\mathrm{CaO}$ & $\mathrm{K}$ & 288434 & $1,05 \pm 0,01 \%$ \\
\hline 2 & 14 & $\mathrm{SiO}_{2}$ & $\mathrm{~K}$ & 2163671 & $73,71 \pm 0,07 \%$ \\
\hline 3 & 13 & $\mathrm{Al}_{2} \mathrm{O}_{3}$ & $\mathrm{~K}$ & 259160 & $16,69 \pm 0,07 \%$ \\
\hline 4 & 19 & $\mathrm{~K}_{2} \mathrm{O}$ & $\mathrm{K}$ & 920072 & $4,20 \pm 0,01 \%$ \\
\hline 5 & 26 & $\mathrm{Fe}_{2} \mathrm{O}_{3}$ & $\mathrm{~K}$ & 3810780 & $1,36 \pm 0,00 \%$ \\
\hline 6 & 16 & $\mathrm{~S}$ & $\mathrm{~K}$ & 1317455 & $1,25 \pm 0,00 \%$ \\
\hline 7 & 12 & $\mathrm{MgO}$ & $\mathrm{K}$ & 5253 & $0,94 \pm 0,09 \%$ \\
\hline 8 & 22 & $\mathrm{TiO}_{2}$ & $\mathrm{~K}$ & 447709 & $0,69 \pm 0,00 \%$ \\
\hline
\end{tabular}

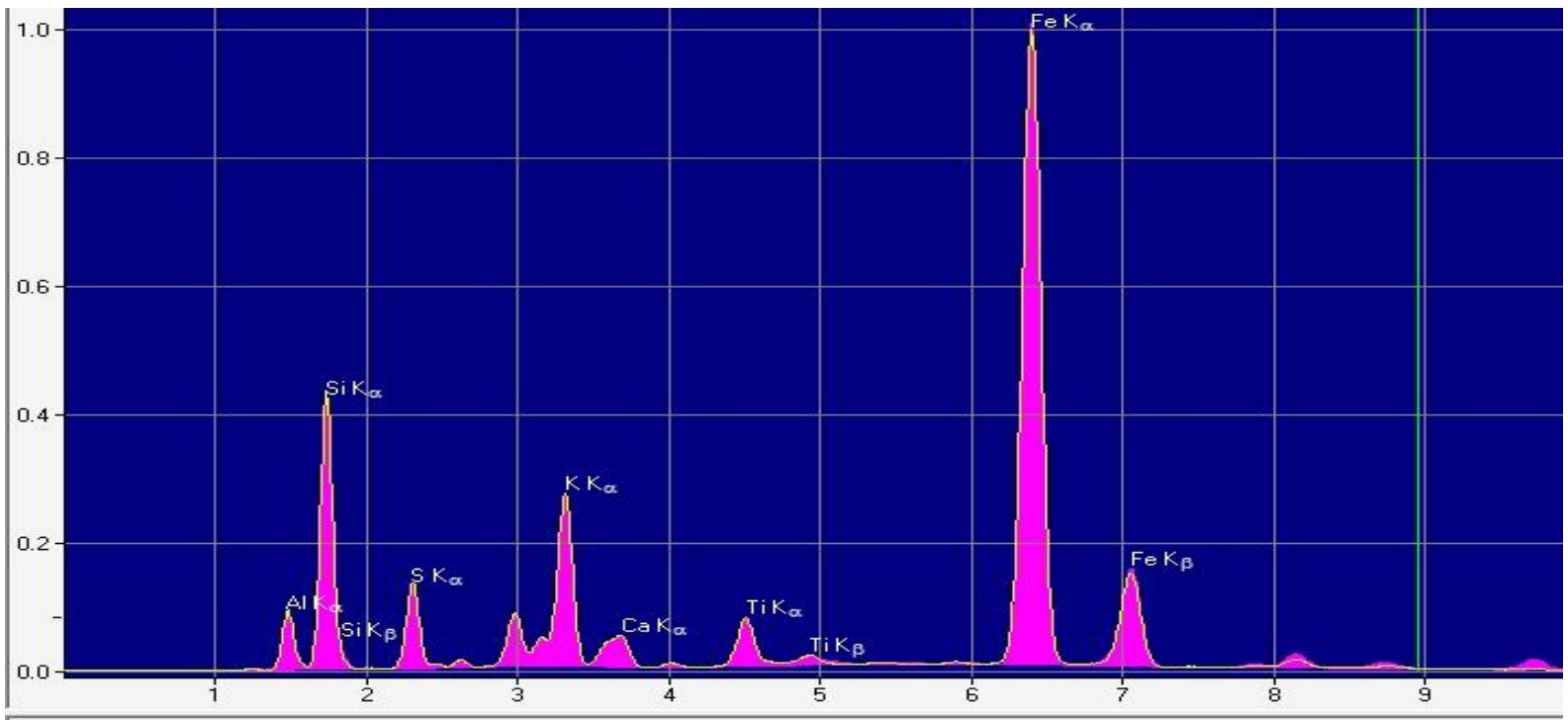

Рис. 6. Спектрограмма содержания химических элементов в образие породы № 2

Выводы. На основе проведенного рентгенофлуоресцентного исследования получено представление о составе химических элементов, что дает возможность сравнения химических элементов до и после горения породы. Разница по диоксиду кремния $\left(\mathrm{SiO}_{2}\right)$ составила - 8,58 \%; оксид алюминия $\left(\mathrm{Al}_{2} \mathrm{O}_{3}\right)-$ $6,76 \%$; оксид калия $\left(\mathrm{K}_{2} \mathrm{O}\right)-0,72 \%$; серы $(\mathrm{S})-0,7 \%$. По интенсивности альфаоблучения: оксид железа $\left(\mathrm{Fe}_{2} \mathrm{O}_{3}\right)-\mathrm{K} \alpha=1778901$; диоксид кремния $\left(\mathrm{SiO}_{2}\right)-\mathrm{K} \alpha=601591$; оксид калия $\left(\mathrm{K}_{2} \mathrm{O}\right)-\mathrm{K} \alpha=56319$; серы (S) $-\mathrm{K} \alpha=801466$.

\section{Список использованной литературы:}

1. Чоботько I.I. Технологічна схема пристрою зрошування вапнякової суспензії консольного відвалоутворювача ВКР 8000/100 / І.І. Чоботько, С.В. Тинина, В.П. Франчук // ВІСТІ Донецького гірничого інституту. - Покровськ : Донецький національний технічний університет. - 2019. - № 1 (44). - С. 138-144.

2. Чоботько I.I. Методи та засоби локалізації осередків самозаймання породних відвалів / I.I. Чоботько, C.B. Тинина // Геотехнічна механіка : міжвідомчий зб. наук. праць. - Дніпро, 2018. - Вип. 142. - С. 134-139. 
3. Чоботько I.I. Проблеми експлуатації та методи запобігання загоранню породних відвалів / I.I. Чоботько, C.B. Тинина // Вісник Національного технічного університету «ХПІ». Серія: Механіко-технологічні системи та комплекси. - 2017. - Т. 44. - С. 146-151.

4. Зубов А.Р. Экспетрная система оценки породных отвалов угольных шахт как структурных элементов экологических сетей / A.P. Зубов, А.А. Зубов // Уголь Украины. - Киев, 2016. - № 2. - С. 31-37.

5. Зубова Л.Г. Оценка радиоактивности породных отвалов уголных шахт ПАО «Лисичанскуголь» / Л.Г. Зубова, А.Р. Зубов // Уголь Украины. - Киев, 2016. - № 4-5. - С. 59-65.

6. Верех-Білоусова К.Й. Оцінка впливу породного відвалу вугільної шахти на грунти прилеглих територій / К.Й. Верех-Білоусова // Уголь Украины. - Киев, 2016. - № 4-5. - С. 66-67.

7. Зубова Л.Г. Породы отвалов угледобычи как сырье для металлургии / Л.Г. Зубова // Уголь Украины. - Киев, 2016. - № 11-12. - С. 45-53.

8. Зборщик М.П. Природа самовозгорания и тушения отвальных пород угольных месторождения / М.П. Зборщик, В.В. Осокин // Уголь Украины. - Киев, 2015. - № 3-4. - С. 76-78.

9. Греков С.П. Расчет выделения вредных веществ из породных отвалов / С.П. Греков, И.Н. Зинченко, Е.А. Головченко // Уголь Украины. - Киев, 2010. - № 2. - С. 20-21.

10. Мнухин А.Г. Породные отвалы - сырье будущего / А.Г. Мнухин // Уголь Украины. - Киев, 2009. - № 5. C. $28-32$.

11. Пашковский П.С. Контроль теплового состояния породных отвалов / П.С. Пашковский, Э.А. Попов, М.A. Яремчук // Уголь Украины. - Киев, 2000. - № 7. - С. 27-29.

12. Збориик М.П. Предотвращение экологически вредных проявлений в породах угольных месторождений / М.П. Зборщик, В.В. Осокин. - Донецк : Донецкий государственный технический университет, 1996. -178 с.

\section{References:}

1. Chobot'ko, I.I., Tynyna, S.V. and Franchuk, V.P. (2019), «Tehnologichna shema prystroju zroshuvannja vapnjakovoi' suspenzii' konsol'nogo vidvaloutvorjuvacha VKR 8000/100», VISTI Donec'kogo girnychogo instytutu, Donec'kyj nacional'nyj tehnichnyj universytet, Pokrovs'k, No. 1 (44), pp. 138-144.

2. Chobot'ko, I.I. and Tynyna, S.V. (2018), «Metody ta zasoby lokalizacii' oseredkiv samozajmannja porodnyh vidvaliv», Mizhvidomchyj zbirnyk naukovyh prac' «Geotehnichna mehanika», Dnipro, Issue 142, pp. 134-139.

3. Chobot'ko, I.I. and Tynyna, S.V. (2017), «Problemy ekspluatacii' ta metody zapobigannja zagorannju porodnyh vidvaliv», Visnyk Nacional'nogo tehnichnogo universytetu «HPI», Serija Mehaniko-tehnologichni systemy ta kompleksy, Vol. 44, pp. 146-151.

4. Zubov, A.R. and Zubov, A.A. (2016), «Jekspetrnaja sistema ocenki porodnyh otvalov ugol'nyh shaht kak strukturnyh jelementov jekologicheskih setej», Ugol' Ukrainy, Kiev, No. 2, pp. 31-37.

5. Zubova, L.G. and Zubov, A.R. (2016), Ocenka radioaktivnosti porodnyh otvalov ugolnyh shaht PAO «Lisichanskugol'», Ugol' Ukrainy, Kiev, No. 4-5, pp. 59-65.

6. Vereh-Bilousova, K.J. (2016), «Ocinka vplyvu porodnogo vidvalu vugil'noi' shahty na grunty pryleglyh terytorij», Ugol' Ukrainy, Kiev, No. 4-5, pp. 66-67.

7. Zubova, L.G. (2016), «Porody otvalov ugledobychi kak syr'e dlja metallurgii», Ugol' Ukrainy, Kiev, No. 11-12, pp. $45-53$.

8. Zborshhik, M.P. and Osokin, V.V. (2015), «Priroda samovozgoranija i tushenija otval'nyh porod ugol'nyh mestorozhdenija», Ugol' Ukrainy, Kiev, No. 3-4, pp. 76-78.

9. Grekov, S.P., Zinchenko, I.N. and Golovchenko, E.A. (2010), «Raschet vydelenija vrednyh veshhestv iz porodnyh otvalov», Ugol' Ukrainy, Kiev, No. 2, pp. 20-21.

10. Mnuhin, A.G. (2009), «Porodnye otvaly - syr'e budushhego», Ugol' Ukrainy, Kiev, No. 5, pp. 28-32.

11. Pashkovskij, P.S., Popov, Je.A. and Jaremchuk, M.A. (2000), «Kontrol' teplovogo sostojanija porodnyh otvalov», Ugol' Ukrainy, Kiev, No. 7, pp. 27-29.

12. Zborshhik, M.P. and Osokin, V.V. (1996), Predotvrashhenie jekologicheski vrednyh projavlenij $v$ porodah ugol'nyh mestorozhdenij, Doneckij gosudarstvennyj tehnicheskij universitet, Doneck, 178 p.

Чоботько Игорь Игоревич - аспирант кафедры инжиниринга и дизайна в машиностроении Национального технического университета «Днепровская политехника».

Научные интересы:

- отраслевое машиностроение;

- геотехническая и горная механика.

E-mail: efilonov79@gmail.com.

Тынына Сергей Владимирович - кандидат технических наук, старший научный сотрудник отдела механики эластомерных конструкций горных машин Института геотехнической механики им. Н.С. Полякова НАН Украины.

Научные интересы:

- геотехническая и горная механика.

E-mail: haritonroots@gmail.com. 